\title{
CFD NUMERICAL ANALYSIS OF A PROPOSED CHANGE IN THE CHANNEL GEOMETRY DOWNSTREAM OF A REVERSED TAINTER GATE
}

\author{
M. D. Corte ${ }^{\mathrm{a}}$, \\ R. C. Oliveski ${ }^{\mathbf{a}}$, \\ M. G. Marques ${ }^{b}$, \\ and M. Dai Prac \\ ${ }^{a}$ Universidade do Vale do Rio dos Sinos \\ Programa de Pós-Graduação em Engenharia Mecânica \\ Laboratório de Simulação Numérica \\ CEP 93022-000, São Leopoldo, Rio Grande do Sul, Brasil \\ marcelodallacorte@gmail.com \\ bUniversidade Federal do Rio Grande do Sul \\ Instituto de Pesquisas Hidráulicas \\ CEP 91501-970, Porto Alegre, Rio Grande do Sul, Brasil \\ ${ }^{\mathrm{c}}$ Universidade Federal de Pelotas \\ Programa de Pós-Graduação em Recursos Hídricos \\ CEP 96010-610, Pelotas, Rio grande do Sul, Brasil \\ decesaroo@gmail.com \\ Received: March 04, 2015 \\ Revised: April 06, 2015 \\ Accepted: May 072015
}

\section{ABSTRACT}

Reversed Tainter gates are often used to control flow in the filling and emptying locks navigation systems of high fall. High speeds and pressure fluctuations may occur in the flow downstream of these gates, the flow cavitation may occur, damaging the structure. One way proposed to mitigate this problem is through geometric changes in the channel downstream of the gate. In this study was analyzed using CFD the effect of an expansion in the roof and the base of the conduit, followed by a straight section and a subsequent contraction until returning to the original geometry. It was observed that the pressure at the base of the conduit increases with the modification, however peaks of positive and negative pressures occur due to the shape change of the geometry of the corners not be smooth. The size of recirculation downstream of the gate increases with the geometrical alteration, increasing the distance required for pressure recovery.

\section{NOMENCLATURE}

a Floodgate's percentual opening

B Conduit Height

b Opening Height

bCc Vena contracta's height

Cc Contraction coefficient

$\Delta \mathrm{h} \quad$ Maximum pressure variation

$\mathrm{H}_{\mathrm{L}} \quad$ Head Loss

Q Volumetric flow

$\mathrm{V} \quad$ Average speed of entry

V2 Vena’s average speed

\section{INTRODUCTION}

Lock navigation systems are structures built to allow vessels to transpose height gaps, whether natural (waterfalls and isthmus) or due to human action (dams), in an efficient and safe manner. The lock consists of: a chamber (in which it's possible to change the water level due to upstream and downstream external conditions through the communicating vessels principle), a water distribution system and lower and upper approach channels. The locks are classified according to their height gap (the difference between the upstream and downstream water levels), which can be: low drop $(\leq 10 \mathrm{~m})$, medium drop (10 to $15 \mathrm{~m})$ or high drop $(\geq 15 \mathrm{~m})$.

Among the main design problems found in the high drop category stands out: lashing conditions of the ships on the chamber. To ensure the vessels' safety, the water surface movement in the chamber must be uniform, therefore a hydro-dynamically stable system must be used.

Another critical point in the high drop systems occurs in the filling and emptying system's locks. In these locks, reversed tainter gates are often used in the flow control. Figure 1 shows a scheme of this gate type, where the main channel, the stack of equilibrium and the gate, as well as the recirculation zone, that occurs after the gate.

The big pressure difference between the floodgate's faces and the short operation times incur high velocities, high fluctuations and high pressure drops near the floodgates. These flow conditions increase the chances of cavitation and erosion in the distribution system's walls. Besides erosion and cavitation, vibrations may occur in the floodgate, 
causing spasmodic efforts in the flow machinery and increasing in the efforts linked to the downpull and uplift phenomena (due to the ascending and descending thrust of the floodgate)[6]. However, the cavitation downstream of the locks is the worst problem and is one of the main limitations to increased the locks project height $[4,10]$.

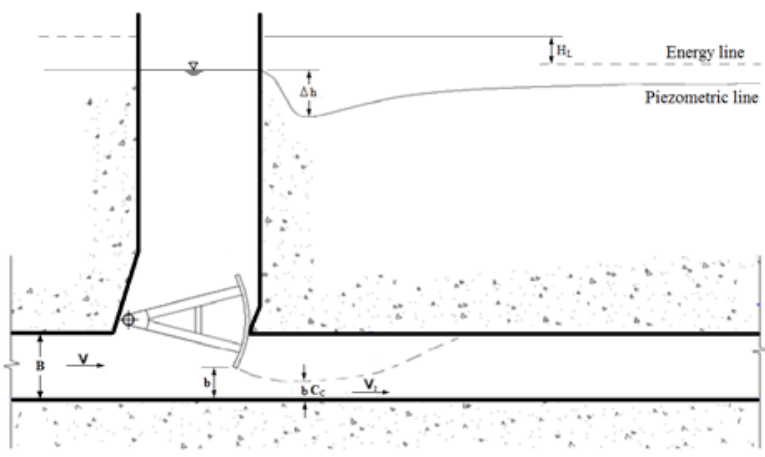

Figure 1. Reversed tainter gate operating sketch.

In order to reduce the damage caused by cavitation, a few techniques are being used: resistant coatings, utilization of special techniques when opening the floodgates, geometric alterations on the conduit and controlled air additions [8, 6].

Air addition is one of the most common techniques to reduce the damage caused by cavitation in hydraulic structures. However, its use in lock navigation systems is limited to small quantities in order to avoid air pockets from forming in the distribution system, which, when expelled in the chamber, causes the water surface to stir, causing increased efforts in the mooring systems, or even accidents with the vessels. The resistant coating application increases the project cost by a large amount and the use of special techniques for floodgates openings may not be possible due to limitation in the floodgate actuation system. Geometric alterations in the downstream conduit are a promising and low cost solution. Studies conducted by Pickering (1981 apud [9]) and Santos et al [7] in expansions on the conduit top have shown significant results in terms of cavitation potential.

This paper's objective is to analyze the effects of a geometric alteration on the downstream conduit of a reversed tainter gate through numerical simulation. The results obtained with the model were compared to numerical results obtained with a model without alteration. The main flow characteristics were analyzed in order to evaluate the reduction in cavitation potential downstream of the floodgate with the proposed geometric alteration.

\section{MATERIALS AND METHODS}

The numerical analysis performed in this paper utilized an experimental test bench (developed by the IPH-UFRGS Laboratory) as reference. The test bench seeks to reproduce a reversed tainter gate and a section of the downstream and upstream galleries of a lock navigation system filling and emptying system, as shown in Figure 2.

The test bench conduit has $0.25 \mathrm{~m}$ side square section, with $1.7 \mathrm{~m}$ in length upstream and $4 \mathrm{~m}$ downstream. The chamber's length is $0.4 \mathrm{~m}$ and its height is $0.75 \mathrm{~m}$. The balancing chimney has a diameter of $0.1 \mathrm{~m}$ and is $2.5 \mathrm{~m}$ height. The floodgate's bend radius is $0.38 \mathrm{~m}$, allowing it to control its opening from $0 \%$ to $100 \%$. The floodgate's opening (a) is defined in percentual terms, as the ratio between the floodgate's inferior edge to the bottom of the conduit and the conduit's height downstream of the floodgate.

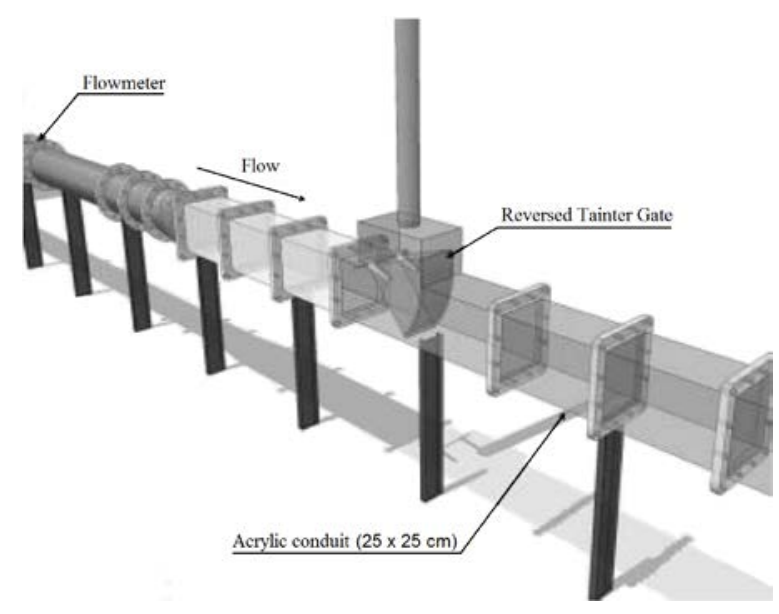

Figure 2. Original test bench schematic drawing.

On the main conduit, downstream of the floodgate, pressure gauges were installed on the top and bottom, in such a way that it was possible to measure the pressure using piezometers and electrical transducers. Another transducer was installed on the chamber entrance's base to allow the analysis of the pressure drop on the navigation lock. More details on the experimental studies developed by the IPHUFRGS can be obtained in Mees et al. [5] and Battiston et al. [2].

This study aimed to analyze the effect of a geometric change in the top and base of the conduit downstream of the reversed tainter gate on the flow characteristics using computational fluid dynamics (CFD). The results obtained in this work were compared to Dalla Corte [3], where the same methodology was used in this study to analyze numerically the flow observed on the IPH-UFRGS test bench described above. In this work, the unchanged numerical model geometry will be called "original" and the changed model geometry will be called "new".

The flow's numerical simulation was done through the commercial software ANSYS CFX-14. The numerical model's geometry (the original, as well as the new) were simplified (the axis and the support arms were not considered), however the 
dimensions used were equal to those of the test bench. Besides, a symmetry condition of the flow was considered in the width direction. Thus, the numeric model corresponds to half of the physical model, as observed in Figure 3. The proposed and studied geometric change consists in an expansion on the top and base of the conduit, downstream of the floodgate, with a slope of $10 \%$ and length of $0.6 \mathrm{~m}$, followed by a $0.6 \mathrm{~m}$ section and then a reduction, also with a $10 \%$ slope and $0.6 \mathrm{~m}$ length, returning to the original dimensions of the conduit. Figure 4 shows the geometry of numerical model with the top and base alterations.

The spacial mesh used is of the hexahedral type, built with the multi-block technique. Figure 5 shows a section of the geometry's computational mesh in the new floodgate region. The mesh used in the original geometry has approximately 6.6x105 elements, while the mesh used in the new geometry has, approximately, $1.5 \times 106$ elements. It was necessary to use a higher element number in the new geometry to properly capture the pressure peaks that happen in the geometry's edge.

The computational model is biphasic homogeneous, comprising of the mass and momentum conservation equations, volume fraction equation and the turbulence model equations. The turbulence model used is $\kappa-\varepsilon$ since it is simple and robust. All simulations were conducted in steady state. The boundary conditions used in the inlet were: a developed velocity profile, turbulent kinetic energy and dissipation rate. On the outlet, an expression for the change in hydrostatic pressure in fuction of the height was applied, based on pressure results obtained experimentally for each flow rate. On the walls, a non-slip condition was used, except on the chimney walls, where a free-slip condition was used to simplify the model. The chimney opening was prescribed as static pressure equal to 0 . On the symmetry plane it was used a symmetry boundary condition.

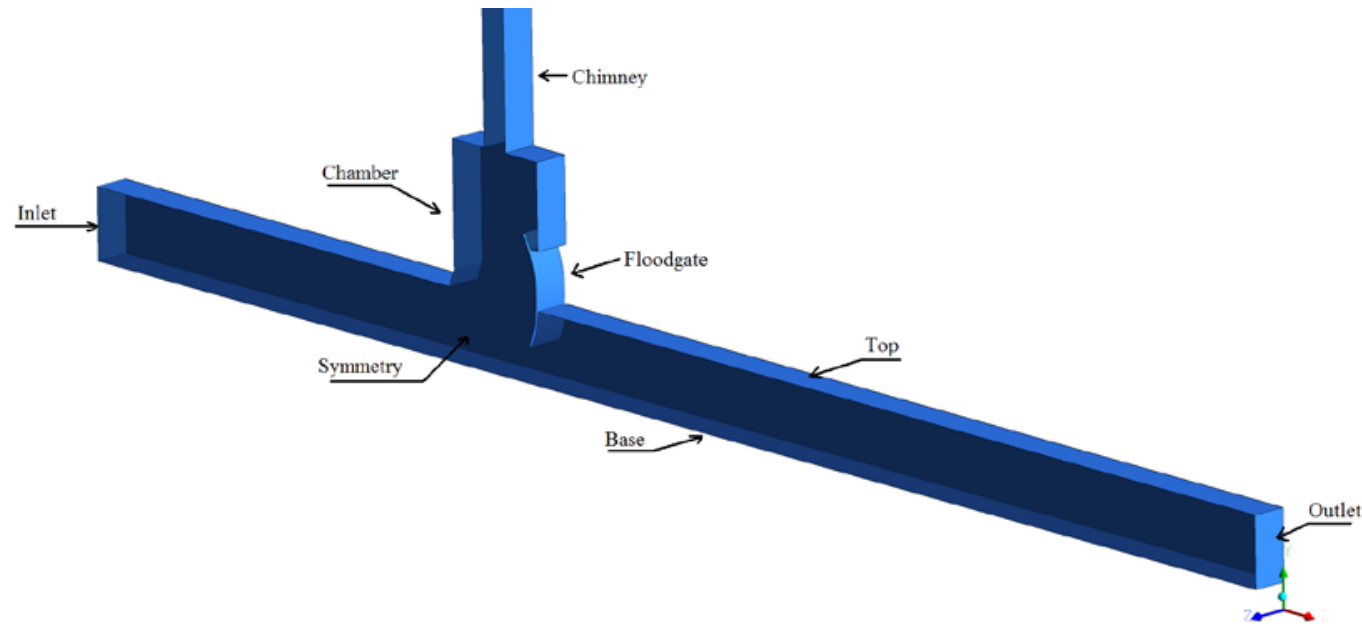

Figure 3. Computational domain - original geometry.

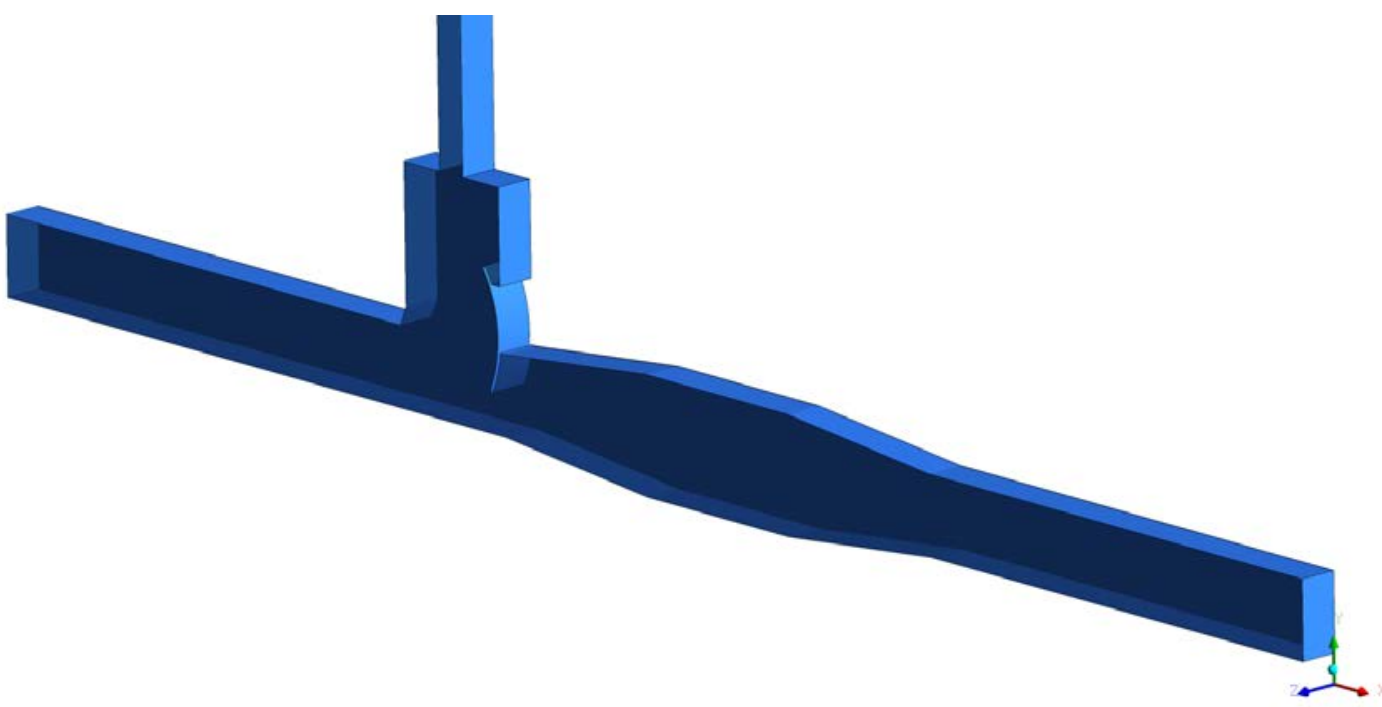

Figure 4. Computational domain - new geometry. 


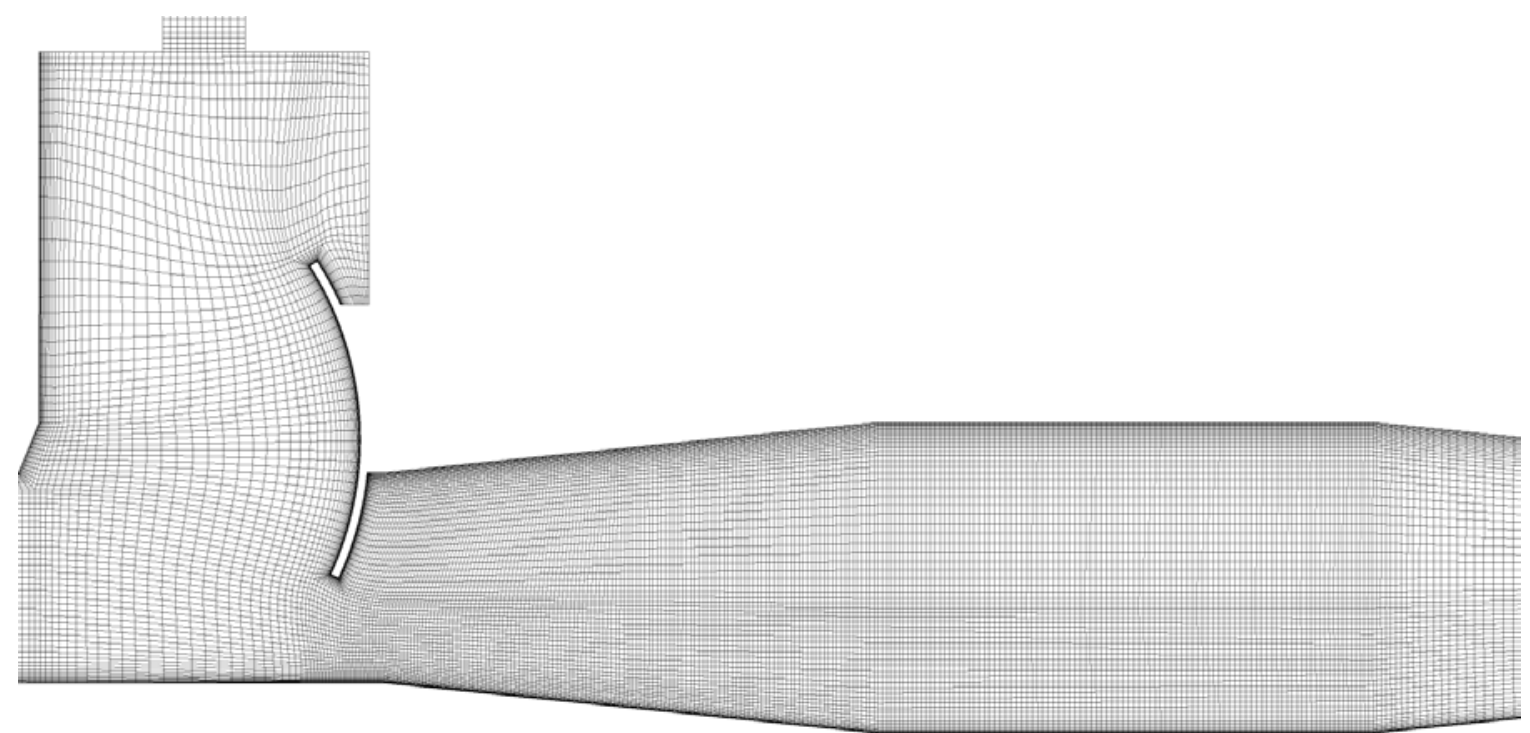

Figure 5. New geometry computational grid detail.

In all studied cases, it was necessary to perform a preliminary simulation (with the same mesh and boundary conditions), but with a "Local Timescale Factor" time step, equal to 5. Additionally, due to the high instability on the velocity fields in the first iterations, a factor of 0.5 was defined separately for the volume fraction equation, to avoid instabilities in the water-air interface height. After that, a second simulation was performed, where the results from the previous one were used as initial conditions for the second one. However, now, with Physical Time Step $=0.005 \mathrm{~s}$ in all domains and for all equations. The same boundary conditions were used on both simulations. The number of iterations was set as 1000 and the "High Resolution" resolution scheme was applied with convergence criterion of $10^{\wedge}-5$. In the first simulation, water level height condition was defined according to the pressure levels obtained in the physical model, obtained in a specific point at the conduit base, at the chamber entrance. A hyperbolic tangent function was used to promote a smooth transition between the different fluids at the interface, reducing numerical problems in this region.

\section{RESULTS AND DISCUSSION}

In Figures 6, 7 and 8 pressure profiles at the base and near the conduit top are shown. These were obtained with the original geometry and with the new geometry for: $\mathrm{Q}=90 \mathrm{l} / \mathrm{s}$ and $\mathrm{a}=30,50$ and $70 \%$. Many pressure spikes downstream of the gate can be observed in the pressure profiles (at the conduit's base) of the cases with the new geometry present. These pressure spikes are located near of the edges of the new geometry and occur due to detachments at the expansion start and the contraction end (negative spikes). It can also be observed in every case, that the new geometry presented higher pressure levels at the base upstream of the gate when compared to the original geometry. This indicates that the geometric change increases the flow's pressure drop. However, if the pressure peaks caused by the geometry corners are not considered, the new geometry presents higher values of minimum pressure downstream of the gate than the ones observed in the original geometry. This phenomenon occurs, in part, due to the increase in hydrostatic pressure as the base is lowered. On the conduit's top, the hydrostatic pressure is lowered as the height is increased. In all cases, except in the case with $\mathrm{a}=70 \%$ and $\mathrm{Q}=90 \mathrm{l} / \mathrm{s}$, the pressure on the top and on the conduit's base, just downstream of the gate, on the new geometry is higher than the levels on the original geometry. However, after this section, the pressure on the new geometry is lower, showing that the pressure recovery in the new geometry is more gradual.

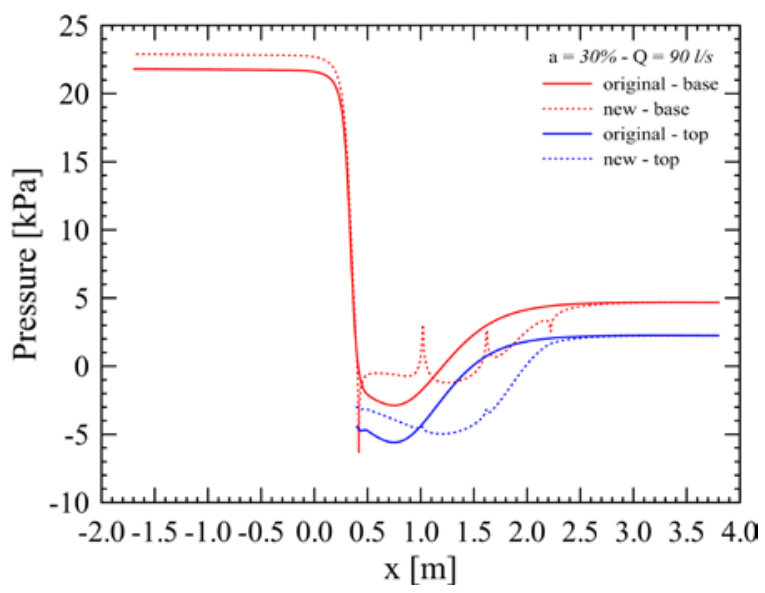

Figure 6. Pressure profiles at the base and roof for the case with $a=30 \%$ and $Q=90 \mathrm{l} / \mathrm{s}$. 


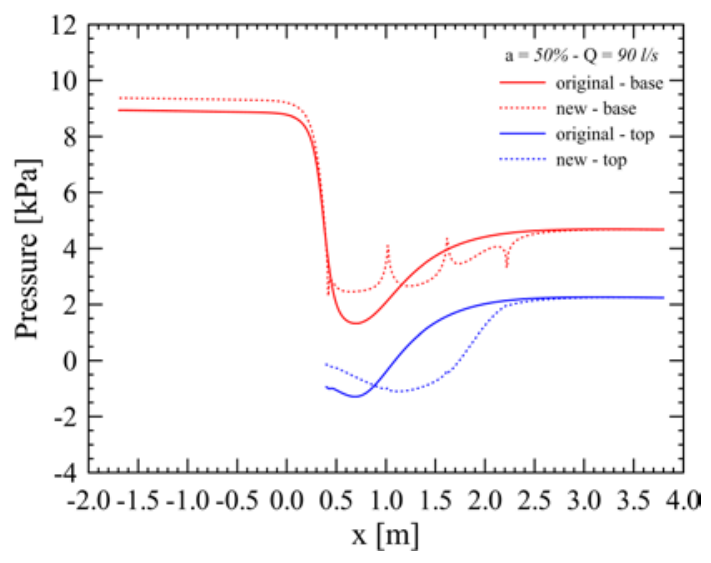

Figure 7. Pressure profiles at the base and roof for the case with $a=50 \%$ and $Q=90 \mathrm{l} / \mathrm{s}$.

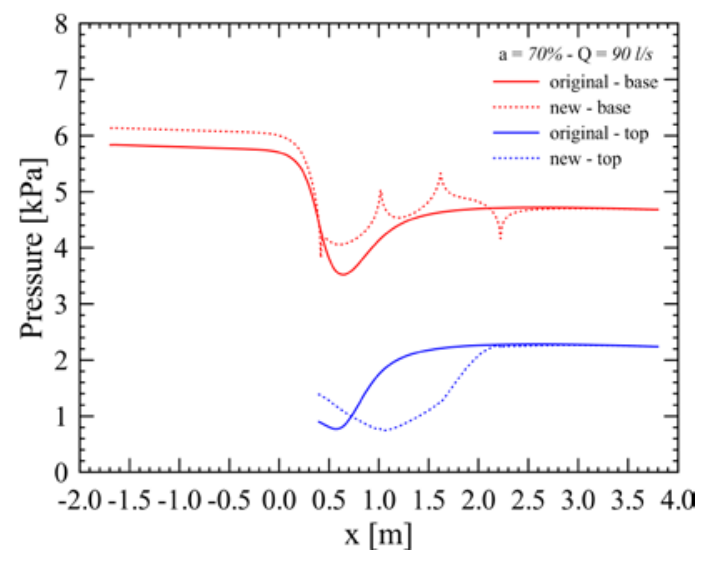

Figure 8. Pressure profiles at the base and roof for the case with $a=70 \%$ and $Q=90 \mathrm{l} / \mathrm{s}$.
Streamlines on the symmetry plane for both geometries and operational conditions of $Q=90 \mathrm{l} / \mathrm{s}$ and $\mathrm{a}=30,50$ and 70\% are shown in Figures 9, 10 and 11. In all cases, it can be seen recirculation's that are formed upstream (within the chamber) and downstream of the gate (due to the formation of the jet below the gate). In the cases with the original geometry, the length of the recirculation region downstream of the gate is significantly reduced as the opening percentual increases. In the cases with the new geometry, the length of this recirculation region is only slightly reduced as the opening percentual is increased. Besides, the recirculation region's length in the new geometry is significantly bigger than the most critical case in the original geometry. This increase in the recirculation region's length downstream of the gate observed in the new geometry is linked to the slower pressure recovery seen in previous figures.

In Figures 12, 13 and 14, velocity fields in the symmetry plane are shown for the original and new geometries, with operational conditions equal to $\mathrm{Q}=90 \mathrm{l} / \mathrm{s}$ and $\mathrm{a}=30,50$ and $70 \%$. In all cases, $\mathrm{a}$ stream with higher velocity forming from the gate can be observed. The maximum stream velocities hardly differ with the geometry differences. In the case where $\mathrm{a}=30 \%$, the stream gets closer to the geometric change end. Also, the stream velocity profile, in the cases with the new geometry, has a disturbance in the end of the expansion region. Another important characteristic observed is that in the cases with the new geometry, the base expansion causes the stream to change directions, making it follow in the same direction as the base's expansion.
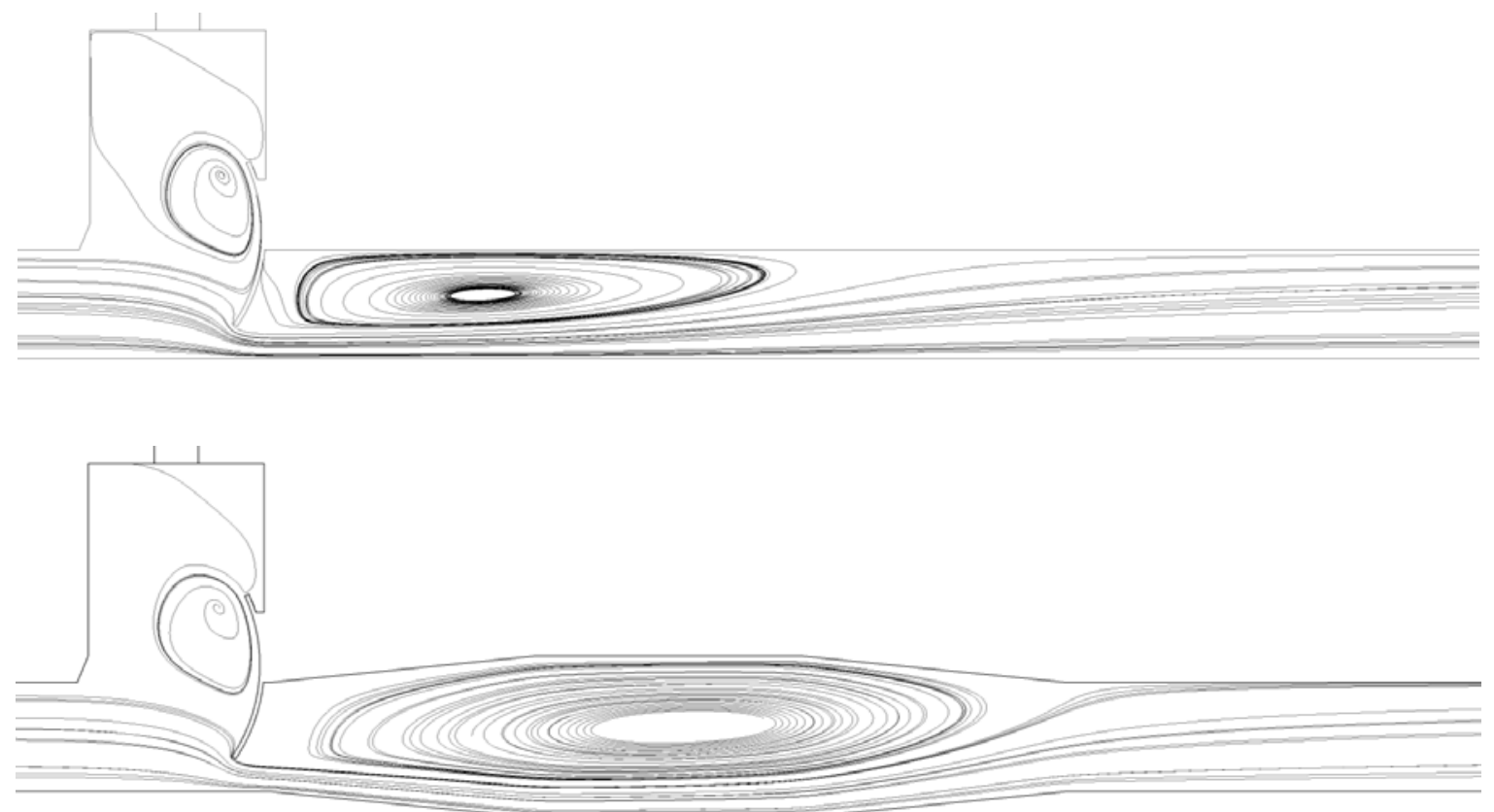

Figure 9. Streamlines at the symmetry plane for the original and new geometries with $a=30 \%$. 

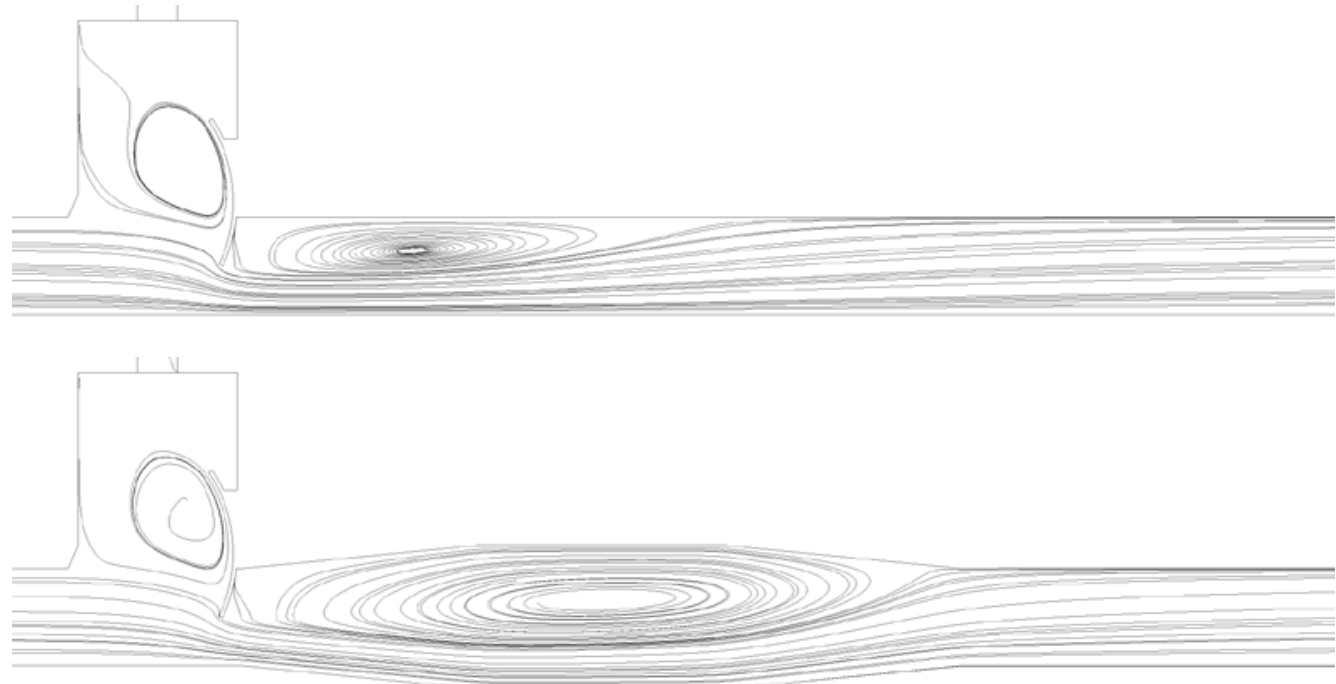

Figure 10. Streamlines at the symmetry plane for the original and new geometries with $a=50 \%$.
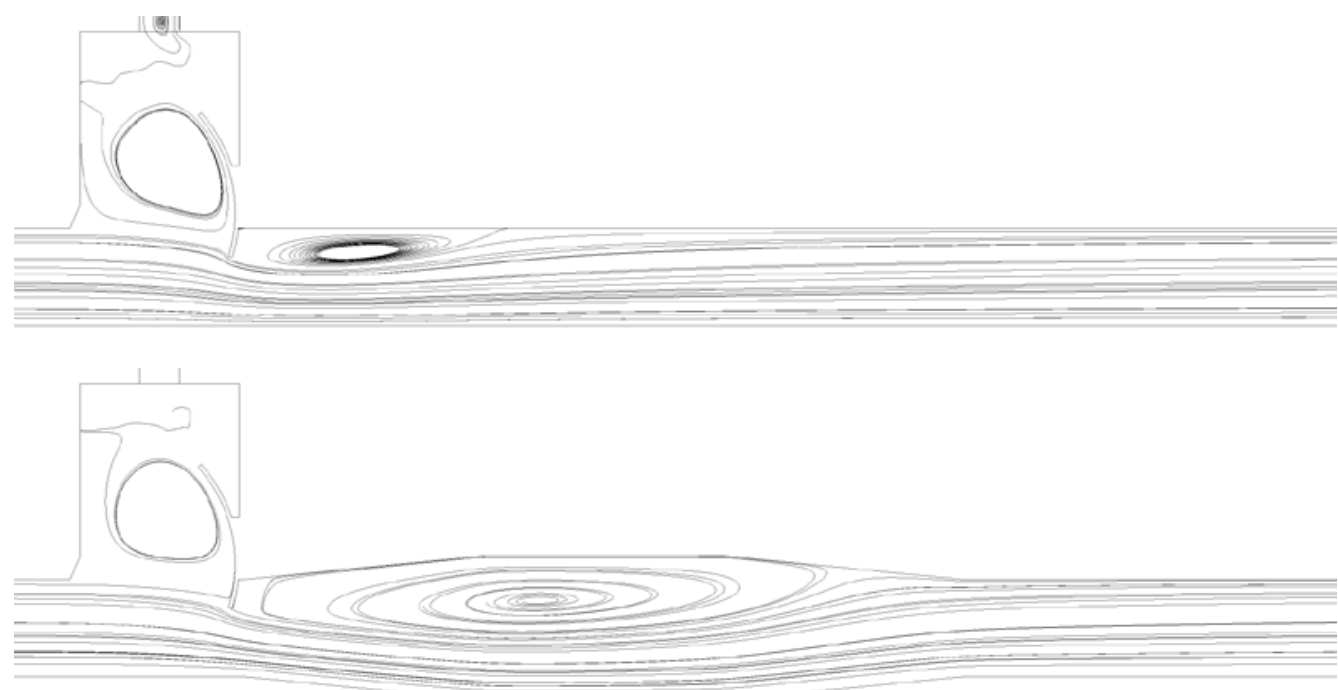

Figure 11. Streamlines at the symmetry plane for the original and new geometries with $a=30 \%$.
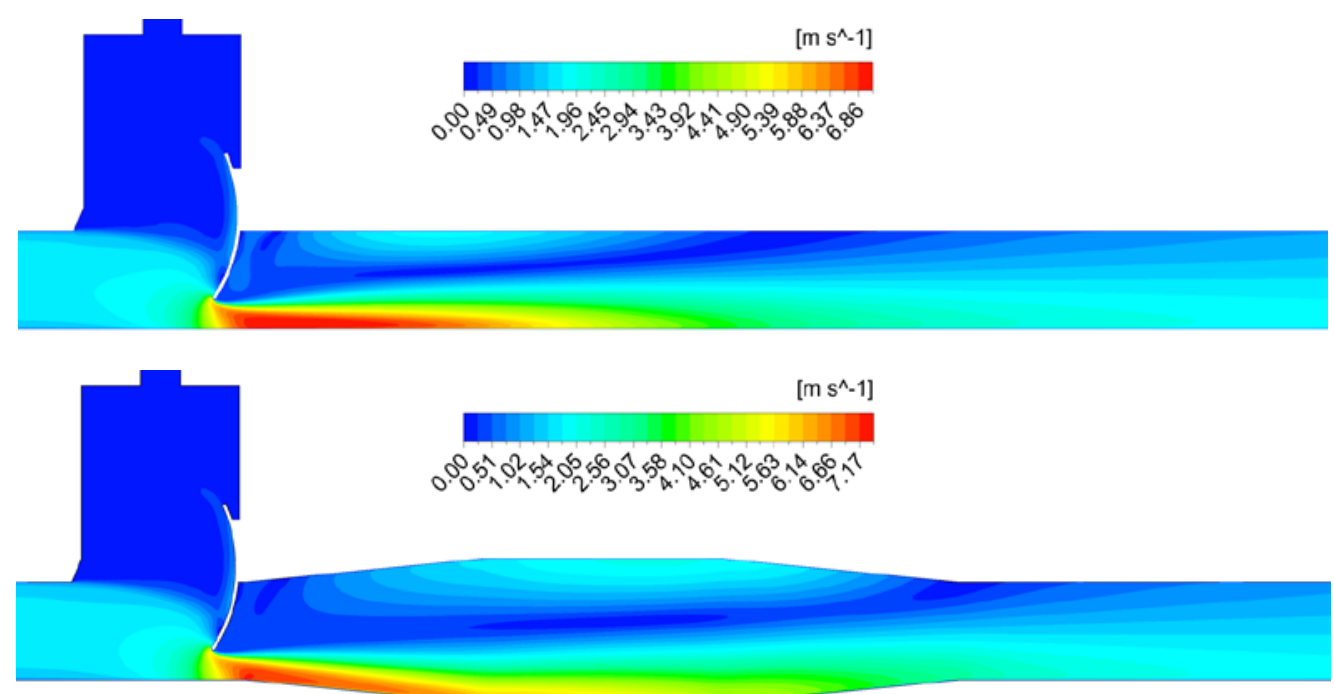

Figure 12 . Velocity field at the symmetry plane for the original and new geometries with $a=30 \%$. 

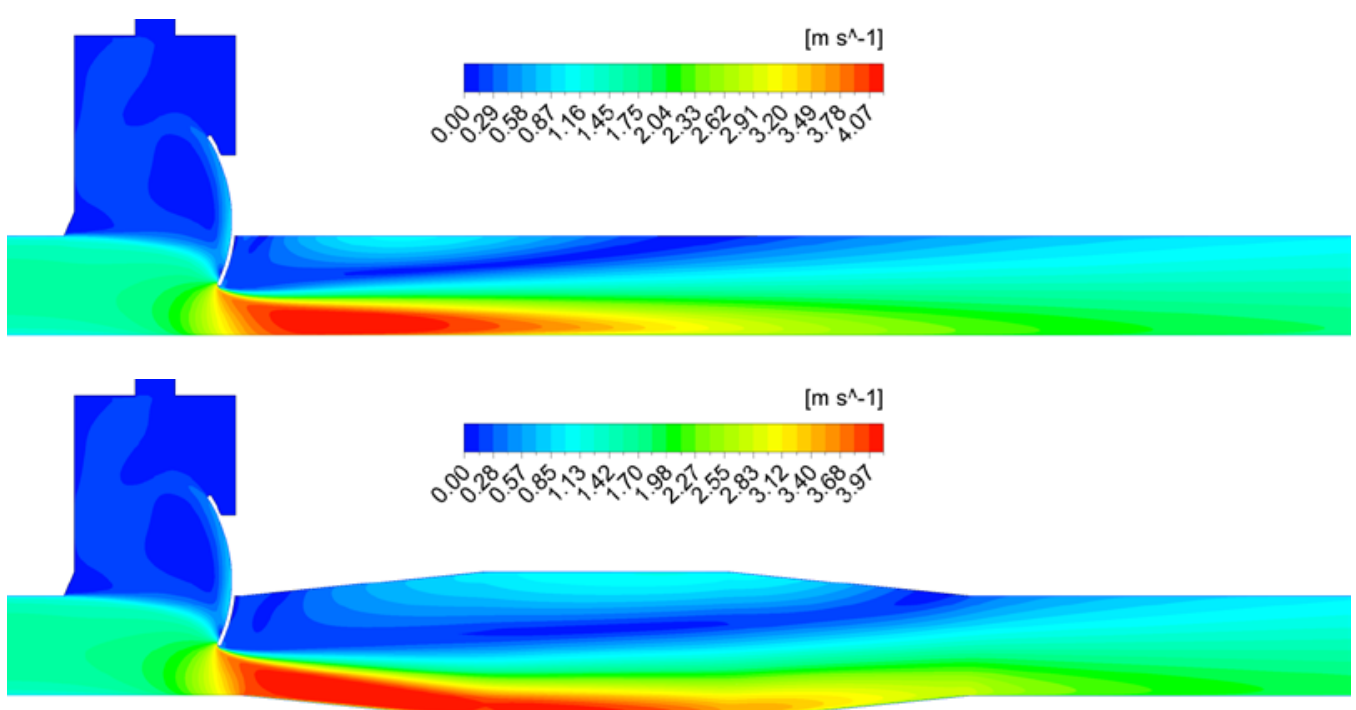

Figure 13 . Velocity field at the symmetry plane for the original and new geometries with $a=50 \%$.
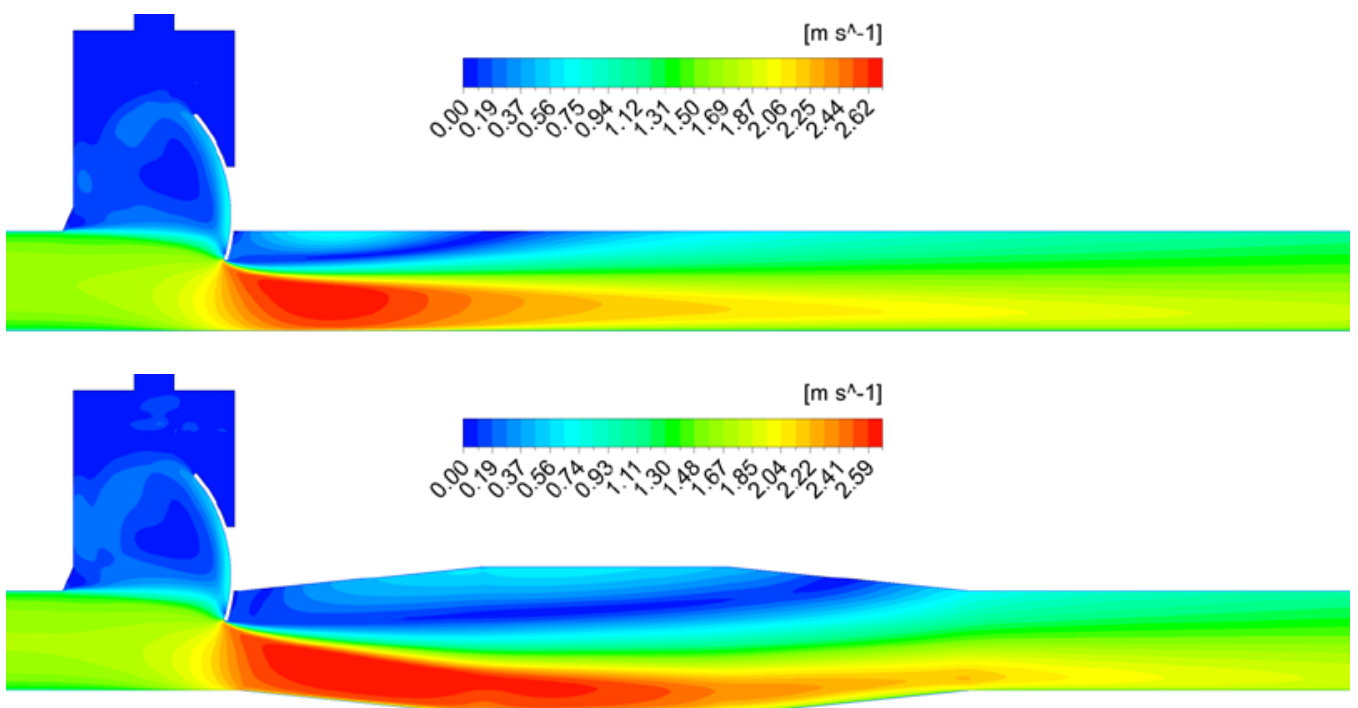

Figure 14 . Velocity field at the symmetry plane for the original and new geometries with $a=70 \%$.

\section{CONCLUSIONS}

This study aimed to analyze the main flow characteristics effects in a geometric change in the conduit downstream of a reversed tainter gate through numeric simulation using CFD. The proposed change consists of an expansion on the top and on the base, just downstream of the gate, and a straight section followed by a contraction to return the original geometry.

It was observed that, in the corners of the geometric changes, pressure spikes occur due to the fact that the geometric changes are not smooth in these regions. However, if these pressure spikes are not taken into account, the pressure at the conduit's base downstream of the gate, in the case with the new geometry, showed higher pressure values than those of the original geometry. It was also observed that the pressure at the conduit's base upstream from the gate was higher in the case with the new geometry when compared to the original one. This indicates that the pressure drop on the floodgate increases with the geometric change downstream of the gate.

Through streamlines in the model's symmetry plane, it was observed that the recirculation that is formed downstream of the gate significantly increases with the geometry alteration. Besides, the size of this recirculation region does not suffer much influence on the floodgate's opening percentual, contrary to what happens in the original geometry, where the recirculation region's length is reduced as the opening increases.

It was also observed that the stream which forms downstream of the gate changes directions and 
follow almost the same direction as the base's expansion. However, the stream's length increases due to the geometric change.

We highlight the importance of numerically analyzing other geometric changes in order to find a geometry that presents better flow characteristics.

The geometry tested in this study is already being tested with the IPH-UFRGS model. In future studies, it is intended to compare the results obtained in the physical and numerical models as to better understand these phenomena.

\section{ACKNOWLEDGEMENTS}

The authors wish to thank FINEP, ANEEL, FAURGS, CAPES and CNPq.

\section{REFERENCES}

Ansys CFX, 2009, Release 11.0 Ansys CFXSolver Modeling Guide, Canonsburg, Ansys, Inc., pp. 626.

Battiston, C. C., Schettini, E. B. C., Canellas, A. V. B., and Marques, M. G. 2009, Eclusas de Navegação: caracterização Hidráulica do Escoamento a Jusante das Válvulas de Enchimento/Esvaziamento. in: Simpósio Brasileiro De Recursos Hídricos, XVIII, Campo Grande, Anais, Campo Grande, pp. 22-26. (in Portuguese)

Dalla Corte, M., Oliveski, R. C., Marques, M. G., and Kempka, M., 2012, Análise Numérica do Escoamento a Jusante de uma Comporta Segmento Invertida, Estudos Tecnológicos em Engenharia, Vol. 8, No. 2, pp. 49-59. (in Portuguese)

Gontijo, N. T., and Campos, R. G. D., 2005, Estruturas Hidráulicas Seminar: Eclusas, Belo Horizonte, Universidade Federal de Minas Gerais, pp. 29. (in Portuguese)

Mees, A. A. A., Battiston, C. C., and Marques, M. G., 2008, Downstream Flow from Reverse Tainter Gates in Conduits as a Hydraulic Jump, in: International Junior Researcher and Engineer Workshop on Hydraulic Structures, 2, Pisa, pp. 123128.

Santos, S. R., 1998, Projeto Hidráulico de Eclusas de Alta Queda, PhD Thesis, Universidade de São Paulo, São Paulo, SP. (in Portuguese)

Santos, J. B. V., Oliveski, R. C., Marques, M. G., Dai Prá, M., Dalla Corte, M., and Oliveira, L. L. M., 2012, Alteração Geométrica no Teto a Jusante de Comporta do Sistema de Enchimento e Esvaziamento para Eclusa de Navegação: Simulação Numérica do Escoamento e Análise das Pressões no teto do Conduto, in: Congresso Nacional De Engenharia Mecânica, VII, São Luís, pp. 1-8. (in Portuguese)

Ussami, H. 1980, Comportamento Hidráulico dos Sistemas de Enchimento e Esgotamento de Eclusas de Navegação, Master Thesis, Universidade de São Paulo, pp. 198. (in Portuguese)
Bejan, A., 1995, Convection Heat Transfer, 2nd Edition, Wiley. 